\title{
Recovery of silver residues from dental amalgam
}

\author{
Heloísa Aparecida Barbosa da Silva PEREIRA', Flávia Godoy IANO², Thelma Lopes da SILVA ${ }^{3}$, \\ Rodrigo Cardoso de OLIVEIRA ${ }^{4}$, Manoel Lima de MENEZES ${ }^{5}$, Marília Afonso Rabelo BUZALAF ${ }^{6}$
}

\author{
1- Graduate student, Department of Biological Sciences, Bauru School Of Dentistry, University of São Paulo, Bauru, SP, Brazil. \\ 2- Pharm, Department of Biological Sciences, Bauru School of Dentistry, University of São Paulo, Bauru, SP, Brazil. \\ 3- BSc, MSc, Department of Biological Sciences, Bauru School of Dentistry, University of São Paulo, Bauru, SP, Brazil. \\ 4- DDS, MSc, PhD, Associate Professor, Department of Biological Sciences, Bauru School of Dentistry, University of São Paulo, Bauru, SP, Brazil. \\ 5- Chem, MSc, PhD, Associate Professor, Department of Chemistry, School of Sciences, State University of São Paulo, Bauru, SP, Brazil. \\ 6- DDS, MSc, PhD, Full Professor, Department of Biological Sciences, Bauru School of Dentistry, University of São Paulo, Bauru, SP, Brazil.
}

Corresponding address: Marília Afonso Rabelo Buzalaf - Faculdade de Odontologia de Bauru - USP - Departamento de Ciências Biológicas - Al. Octávio Pinheiro Brisolla, 9-75 Bauru-SP, 17012-901 Brasil - Phone: + 551432358246 - Fax + 551432271486 - e-mail: mbuzalaf@fob.usp.br

Received: August 26, 2009 - Modification: July 21, 2009 - Accepted: November 11, 2009

\section{ABSTRACT}

Dental amalgam residues are probably the most important chemical residues generated from clinical dental practice because of the presence of heavy metals among its constituents, mainly mercury and silver. Objective: The purpose of this study was to develop an alternative method for the recovery of silver residues from dental amalgam. Material and Methods: The residue generated after vacuum distillation of dental amalgam for the separation of mercury was initially diluted with $32.5 \% \mathrm{HNO}_{3}$ followed by precipitation with $20 \% \mathrm{NaCl}$. Sequentially, under constant heating and agitation with $\mathrm{NaOH}$ and sucrose, the sample was reduced to metallic silver. However, the processing time was too long, which turned this procedure not viable. In another sequence of experiments, the dilution was accomplished with concentrated $\mathrm{HNO}_{3}$ at $90^{\circ} \mathrm{C}$, followed by precipitation with $20 \% \mathrm{NaCl}$. After washing, the pellet was diluted with concentrated $\mathrm{NH}_{4} \mathrm{OH}$, water and more $\mathrm{NaCl}$ in order to facilitate the reaction with the reducer. Results: Ascorbic acid was efficiently used as reducer, allowing a fast reduction, thus making the procedure viable. Conclusions: The proposed methodology is of easy application and does not require sophisticated equipment or expensive reagents.

Key words: Dental amalgam. Silver. Solid wastes. Environment.

\section{NTRODUCTION}

The unbridled development of the population and industry has led to an increase in the generation of residues ${ }^{2}$. The natural environment is not able to support the increasing exposure to chemical products caused by this development ${ }^{6}$. The acknowledgement that human intervention has been contributing to the deterioration of the natural environment has led several countries to search for alternatives for its restructuring?

Regarding the residues generated in dental practice, the most concerning ones are those deriving from dental amalgam $8,9,14,16$ because this metal alloy has, among its constituents, mercury, silver, tin and copper ${ }^{1,12}$. The use of amalgam separators has been recommended to physically remove dental amalgam from waste water in dental clinics thus reducing the mercury emissions $^{9,18}$.

The most abundant metal in dental amalgam is mercury ${ }^{1}$, and its recovery from dental amalgam has been done using vacuum distillation ${ }^{10,11,13}$. After recovery of mercury, however, other hazardous metals are still left ${ }^{1,5}$, among which, silver is the most abundant ${ }^{1}$. This metal is very dangerous both to aquatic and terrestrial organisms ${ }^{4,6,15,21}$. In humans, silver is metabolized and deposited in subcutaneous fat, and its excessive ingestion generates argyria, a 
cosmetic disorder ${ }^{3}$. In addition, silver is commonly used in the industry and its recovery could allow some financial return ${ }^{3,8}$.

Despite some studies have described processes to recover mercury from dental amalgam ${ }^{10,13}$, only one study focused on the recovery of silver using sucrose as a reducing agent $^{11}$. In the present study, the purpose was to develop an alternative method for the recovery of silver residues from dental amalgam.

\section{MATERI AL AND METHODS}

Dental amalgam residues were received from the dental clinics of Bauru Dental School and Hospital for Rehabilitation of Craniofacial Anomalies (HRAC), University of São Paulo, Bauru, SP, Brazil. The amalgam was initially processed by vacuum distillation for mercury removal ${ }^{10,13}$, generating an amount of 5,516.93 g.

\section{Process of silver recovery using sucrose as a reducing agent}

This process was adapted from the methodology proposed by Lee and Fung ${ }^{11}$ (1980). The amount of samples (residues of dental amalgam after recovering mercury) used ranged between 25 and $150 \mathrm{~g}$. For residue dilution, $32.5 \%$ nitric acid was used for the formation of $\mathrm{AgNO}_{3}$ (aq) (Table 1). The solution containing $\mathrm{AgNO}_{3}$ was collected in another vial, where $20 \%$ $\mathrm{NaCl}$ was added to promote the precipitation of silver as $\mathrm{AgCl}_{2}$ (solid). This pellet was washed with nitric acid and deionized water $(1: 100 \mathrm{v} / \mathrm{v})$ until the supernatant became colorless. In sequence, a solution of sucrose (concentrations ranging between 2.5 and $20 \%$ ) and $\mathrm{NaOH}$ (concentrations ranging between 10 and 40\%) was added to the pellet (Table 1) and, under agitation and heating, the $\mathrm{AgCl}_{2}$ was reduced to $\mathrm{Ag}^{0}$ (Figure 1).

Process of silver recovery using ascorbic acid as a reducing agent

The amount of samples used ranged between 150 and $200 \mathrm{~g}$. The tests were done in duplicates, as displayed in Table 2. For dilution, concentrated nitric acid at $90^{\circ} \mathrm{C}$ was used. The silver nitrate formed was collected in another vial. The precipitation with $20 \% \mathrm{NaCl}$ was then accomplished as described above. After washing with nitric acid and deionized water $(1: 100 \mathrm{v} / \mathrm{v})$, $\mathrm{NH}_{3}{ }^{*} \mathrm{H}_{2} \mathrm{O}$, water and additional $20 \% \mathrm{NaCl}$ were added, in order to solubilize the pellet, thus making easier the reaction with ascorbic acid.

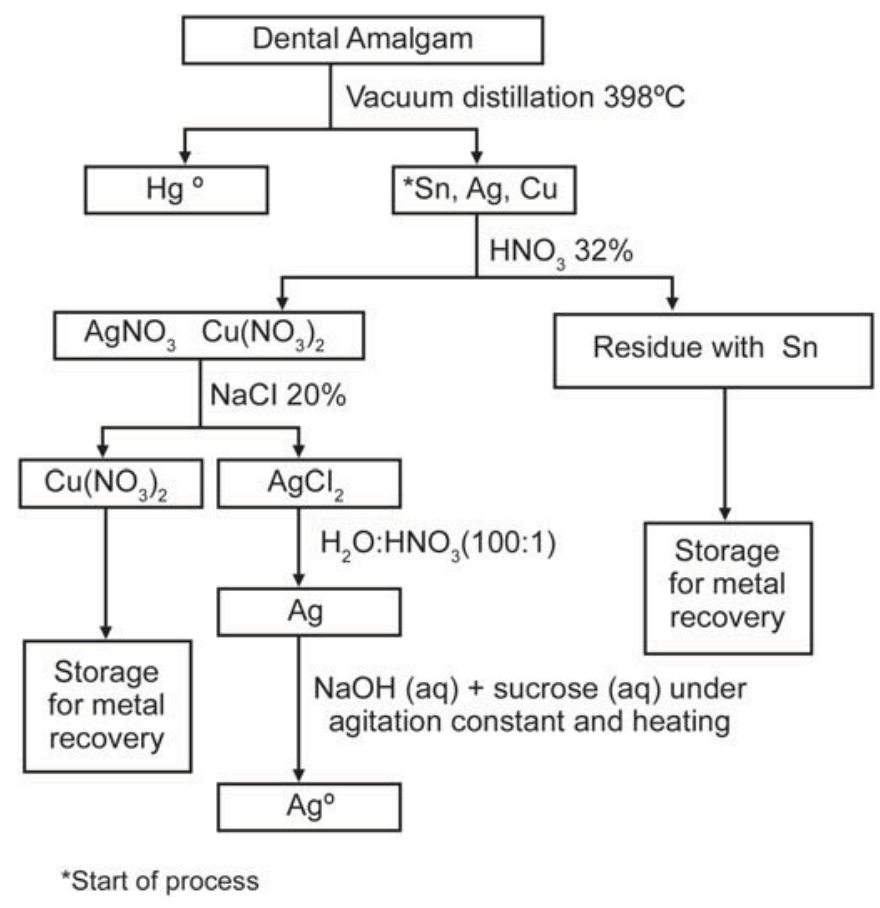

Figure 1- Flow chart of silver recovery using sucrose 
Ascorbic acid (75-100 g, according to the amount of sample) was then added under agitation and silver was immediately reduced to $\mathrm{Ag}^{0}$ (Figure 2).

\section{Analysis of recovery efficiency}

In order to assess the efficiency of recovery, Volhard method was used ${ }^{19}$. Initially, the recovered sample was weighed $( \pm 0.01 \mathrm{mg})$ and then diluted in concentrated nitric acid at $90^{\circ} \mathrm{C}$. The resulting solution was titrated with potassium thiocyanate, in the presence of $\mathrm{Fe}^{2+}$, that was added as a saturated solution of ammonium ferrous sulfate in $20 \%$ nitric acid. In contact with thiocyanate, silver precipitates as AgSCN, which has a very low solubility. A slight excess of

Table 1- Procedure of silver recovery from dental amalgam residues using sucrose as reducing agent

\begin{tabular}{|c|c|c|c|c|c|c|}
\hline \multirow[b]{2}{*}{$\begin{array}{l}\text { Sample } \\
\text { mass }(g)\end{array}$} & \multirow{2}{*}{$\begin{array}{c}\text { Dilution } \\
32.5 \% \text { nitric acid } \\
\text { volume at room } \\
\text { temperature }(\mathrm{mL}) / \\
\text { dilution }\end{array}$} & \multirow{2}{*}{$\begin{array}{l}\text { Precipitation } \\
20 \% \mathrm{NaCl} \\
\text { volume (mL) }\end{array}$} & \multirow{2}{*}{$\begin{array}{c}\mathrm{NaOH} \\
\text { concentration } \\
(\%)\end{array}$} & \multicolumn{2}{|c|}{ Reduction } & \multirow[b]{2}{*}{$\begin{array}{c}\text { Sucrose } \\
\text { volume } \\
\text { (mL) }\end{array}$} \\
\hline & & & & $\begin{array}{c}\mathrm{NaOH} \\
\text { volume } \\
\text { (mL) }\end{array}$ & $\begin{array}{c}\text { Sucrose } \\
\text { concentration } \\
(\%)\end{array}$ & \\
\hline 25.0 & $30.0 / 1$ & 60.0 & 10.0 & 80.0 & 2.5 & 400.0 \\
\hline 50.0 & $50.0 / 1$ & 100.0 & 40.0 & 80.0 & 20.0 & 400.0 \\
\hline 50.0 & $60.0 / 1$ & 120.0 & 20.0 & 80.0 & 5.0 & 400.0 \\
\hline 50.0 & $100.0 / 2$ & 100.0 & 40.0 & 80.0 & 20.0 & 400.0 \\
\hline 110.7 & $300.0 / 3$ & 500.0 & 20.0 & 300.0 & 20.0 & 700.0 \\
\hline 120.0 & $300.0 / 3$ & 500.0 & 20.0 & 750.0 & 20.0 & 1600.0 \\
\hline 134.4 & $300.0 / 3$ & 550.0 & 20.0 & 400.0 & 20.0 & 440.0 \\
\hline 150.0 & $300.0 / 3$ & 500.0 & 20.0 & 750.0 & 20.0 & 2400.0 \\
\hline 150.0 & $350.0 / 4$ & 1200.0 & 20.0 & 800.0 & 20.0 & 1600.0 \\
\hline 150.0 & $300.0 / 3$ & 650.0 & 20.0 & 500.0 & 17.5 & 1100.0 \\
\hline 150.0 & $300.0 / 3$ & 800.0 & 20.0 & 400.0 & 20.0 & 2100.0 \\
\hline
\end{tabular}

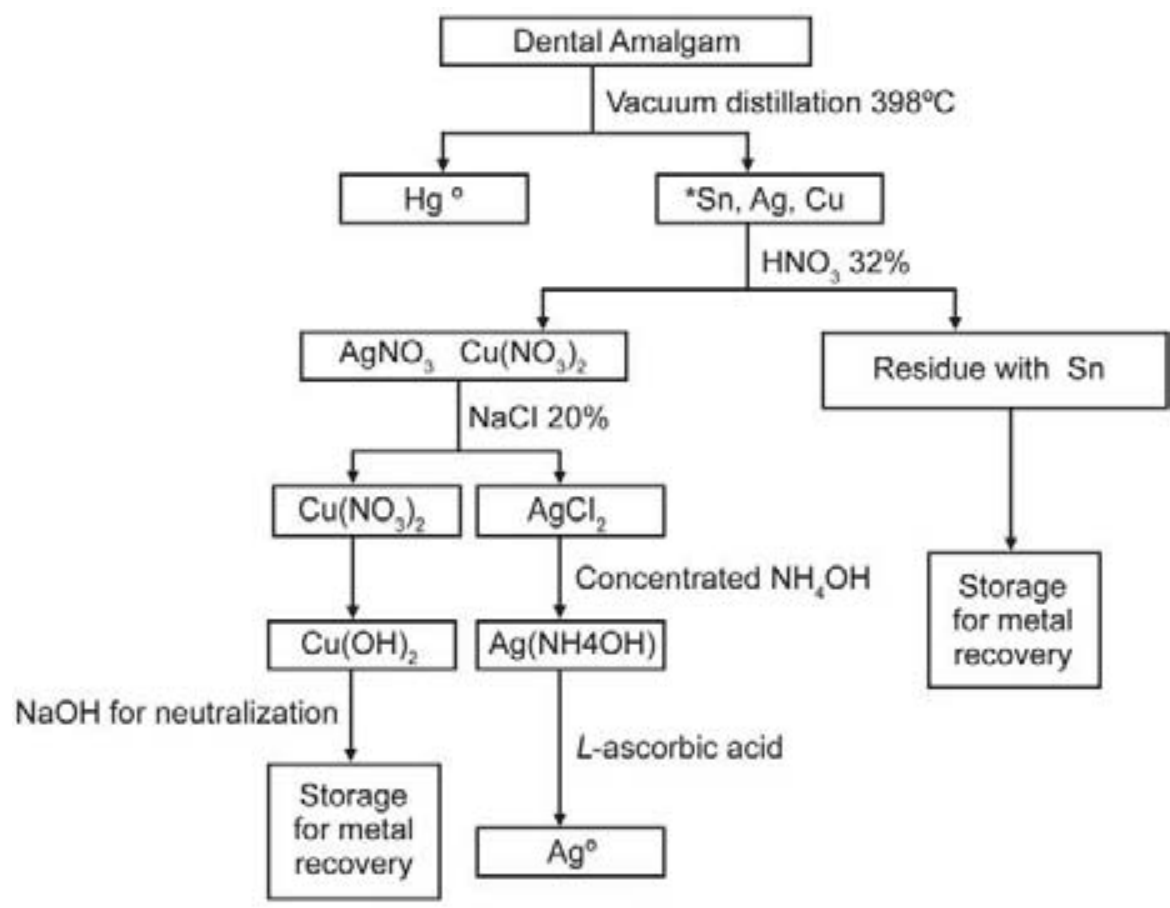

-Start of process

Figure 2- Flow chart of silver recovery using ascorbic acid 
thiocyanate is identified by the formation of a soluble ferric complex $[\mathrm{FeSCN}]^{2+}$, which is intensively stained in red. The titration error in the Volhard method is small as the indicator is extremely sensitive to the thiocyanate ions. The reaction occurs as described below:

$$
1-\mathrm{AgNO}_{3}(\mathrm{aq})+\mathrm{KSCN}-(\mathrm{aq}) \rightarrow \operatorname{AgSCN}(\mathrm{s})
$$
$\mathrm{KNO}_{3}(\mathrm{aq})$

2- $\mathrm{Fe}^{3}+(\mathrm{aq})+\mathrm{SCN}-(\mathrm{aq}) \rightarrow\left[\mathrm{FeSCN}^{2+}(\mathrm{aq})\right.$ (dark red ferric complex)

\section{RESULTS}

Table 3 shows the procedures done for silver recovery using sucrose as reducing agent. The recovery (considering that the \% of silver in dental amalgam is $32.5 \%^{1}$ ) ranged between 23.5 and $61.6 \%$ for the different conditions tested. However, the total time required in the reduction process ranged between 303 and $600 \mathrm{~min}$. The other selected reducing agent was ascorbic acid. The procedures done in the study are described

Table 2- Procedure of silver recovery from dental amalgam residues using ascorbic acid as reducing agent

\begin{tabular}{|c|c|c|c|c|c|c|}
\hline \multirow[b]{2}{*}{$\begin{array}{l}\text { Sample } \\
\text { mass (g) }\end{array}$} & \multirow{2}{*}{$\begin{array}{l}\text { Dilution } \\
\text { Concentrated } \\
\text { nitric acid volume } \\
\text { at } 90^{\circ} \mathrm{C}(\mathrm{mL}) / \\
\text { dilution }\end{array}$} & \multirow{2}{*}{$\begin{array}{l}\text { Precipitation } \\
20 \% \mathrm{NaCl} \\
\text { volume }(\mathrm{mL})\end{array}$} & \multicolumn{2}{|c|}{ Solubilization } & \multirow[b]{2}{*}{$\begin{array}{c}20 \% \mathrm{NaCl} \\
\text { volume }(\mathrm{mL})\end{array}$} & \multirow{2}{*}{$\begin{array}{l}\text { Reduction } \\
\text { Amount of } \\
\text { ascorbic } \\
\text { acid }(g)\end{array}$} \\
\hline & & & $\begin{array}{c}\text { Concentrated } \\
\mathrm{NH}_{4} \mathrm{OH} \text { volume } \\
(\mathrm{mL})\end{array}$ & $\begin{array}{l}\text { Deionized } \\
\text { water } \\
\text { volume } \\
(\mathrm{mL})\end{array}$ & & \\
\hline$A_{1} 150.0$ & $150.0 / 1$ & 300.0 & 500.0 & 1000.0 & - & 75.0 \\
\hline$A_{2} 150.0$ & $150.0 / 1$ & 300.0 & 500.0 & 1000.0 & - & 75.0 \\
\hline $\mathrm{B}_{1} 150.0$ & $500.0 / 5$ & 750.0 & 200.0 & 2000.0 & 1000.0 & 75.0 \\
\hline$B_{2} 150.0$ & $500.0 / 5$ & 750.0 & 200.0 & 2000.0 & 1000.0 & 75.0 \\
\hline$C_{1} 200.0$ & $400.0 / 3$ & 1200.0 & 300.0 & 2000.0 & 1000.0 & 100.0 \\
\hline$C_{2} 200.0$ & $400.0 / 3$ & 1200.0 & 300.0 & 2000.0 & 1000.0 & 100.0 \\
\hline$D_{1} 200.0$ & $500.0 / 5$ & 1200.0 & 300.0 & 2000.0 & 1000.0 & 100.0 \\
\hline$D_{2} 200.0$ & $500.0 / 5$ & 1200.0 & 300.0 & 2000.0 & 1000.0 & 100.0 \\
\hline$E_{1} 200.0$ & $400.0 / 3$ & 1400.0 & 300.0 & 2000.0 & 1500.0 & 100.0 \\
\hline$E_{2} 200.0$ & $400.0 / 3$ & 1400.0 & 300.0 & 2000.0 & 1500.0 & 100.0 \\
\hline$F_{1} 200.0$ & $500.0 / 5$ & 1400.0 & 300.0 & 2000.0 & 1500.0 & 100.0 \\
\hline$F_{2} 200.0$ & $500.0 / 5$ & 1400.0 & 300.0 & 2000.0 & 1500.0 & 100.0 \\
\hline
\end{tabular}

Table 3- Silver recovery from dental amalgam residues using sucrose as reducing agent

\begin{tabular}{|c|c|c|c|c|}
\hline $\begin{array}{l}\text { Sample } \\
\text { mass }(g)\end{array}$ & $\begin{array}{l}\text { Total time } \\
\quad(\min )\end{array}$ & $\begin{array}{l}\text { Amount of } \mathbf{A g}^{0} \\
\text { produced }(g)\end{array}$ & Purity (\%) & $\begin{array}{c}\% \text { recovery }{ }^{a} \\
(32.5 \% \text { of amalgam) }\end{array}$ \\
\hline 25.0 & 303 & 3.9 & 99.9 & 24.4 \\
\hline 50.0 & 430 & 15.5 & 49.3 & 48.4 \\
\hline 50.0 & 360 & 9.2 & 94.2 & 28.8 \\
\hline 50.0 & 373 & 23.0 & 87.1 & 71.9 \\
\hline 110.7 & 390 & 41.5 & 52.6 & 58.6 \\
\hline 120.0 & 330 & 61.1 & 44.1 & 79.6 \\
\hline 134.4 & 455 & 54.0 & 19.6 & 62.8 \\
\hline 150.0 & 600 & 59.1 & 84.1 & 61.6 \\
\hline 150.0 & 440 & 64.5 & 86.0 & 67.2 \\
\hline 150.0 & 365 & 62.1 & 52.9 & 64.7 \\
\hline 150.0 & 565 & 87.9 & 37.0 & 91.6 \\
\hline
\end{tabular}

${ }^{a}$ Based on the American Dental Association $(A D A)^{1}$, which considers that the percentage of silver in dental amalgam is $32.5 \%$. 
Table 4- Procedure of silver recovery from dental amalgam residues using ascorbic acid as reducing

\begin{tabular}{ccccc}
\hline $\begin{array}{c}\text { Sample } \\
\text { mass (g) }\end{array}$ & $\begin{array}{c}\text { Amount of } \mathbf{A g}^{0} \\
\text { produced (g) }\end{array}$ & Purity (\%) & $\begin{array}{c}\text { \% recovery } \\
\text { of amalgam) }\end{array}$ & $\begin{array}{c}\text { Real standard } \\
\text { deviation (\%) }\end{array}$ \\
\hline $\mathrm{A}_{1} 150.0$ & 38.4 & 99.6 & 40.0 & 2.4 \\
$\mathrm{~A}_{2} 150.0$ & 40.9 & 97.0 & 42.6 & 3.9 \\
$\mathrm{~B}_{1} 150.0$ & 83.8 & 78.0 & 87.3 & \\
$\mathrm{~B}_{2} 150.0$ & 76.7 & 80.5 & 79.9 & 11.9 \\
$\mathrm{C}_{1} 200.0$ & 108.0 & 91.1 & 84.4 & 2.4 \\
$\mathrm{C}_{2} 200.0$ & 122.2 & 67.1 & 95.5 & 7.9 \\
$\mathrm{D}_{1} 200.0$ & 57.8 & 99.9 & 45.2 & \\
$\mathrm{D}_{2} 200.0$ & 106.7 & 52.0 & 83.4 & 7.4 \\
$\mathrm{E}_{1} 200.0$ & 111.9 & 72.9 & 87.4 & \\
$\mathrm{E}_{2} 200.0$ & 104.6 & 69.8 & 81.7 & 70.5 \\
$\mathrm{~F}_{1} 200.0$ & 90.2 & 82.7 & 72.4 & \\
$\mathrm{~F}_{2} 200.0$ & 92.7 & 89.8 & & \\
\end{tabular}

${ }^{a}$ Based on the American Dental Association $(A D A)^{1}$, which considers that the percentage of silver in dental amalgam is $32.5 \%$

in Table 4. In this case, the reduction occurred immediately, differently from what was seen when the sucrose was used. In addition, the recovery in this case was higher ( $40 \%$ to $95.5 \%)$ when compared to the use of sucrose as reducing agent.

\section{DISCUSSION}

This is the first study that used ascorbic acid as a reducing agent for recovering silver from dental amalgam. In this study, two methods were tested to recover the silver that is left after the mercury is removed from dental amalgam: one using sucrose as a reducing agent, and the one using ascorbic acid as a reducing agent. The only study in the literature that attempted to recover silver from dental amalgam residues used sucrose as a reducing agent ${ }^{11}$. However, when sucrose was tested as a reducing agent in the present study, the total time required in the reduction process was too long (ranging between 303 and $600 \mathrm{~min}$, depending on the conditions used). Due to this long processing time, a different reducing agent was used in attempt to speed the processing time. The selected reducing agent was ascorbic acid, since it has been reported as a strong reducing agent for metals ${ }^{17}$. In this case, the reduction occurred immediately, differently from what was seen when the sucrose was used. In addition, the recovery was slightly higher when compared to the use of sucrose as reducing agent.

It must be highlighted that some modifications done in the processing technique when the ascorbic acid was used instead of sucrose may have facilitated the reduction process, such as the use of concentrated nitric acid at $90^{\circ} \mathrm{C}$, which allowed a faster and more efficient dilution. In the case of sucrose, dilution was performed by the use of $32.5 \%$ nitric acid at room temperature. Also the use of $\mathrm{NaOH}$ in the case of sucrose leads to the formation of a complex of $\mathrm{AgO}_{2}$, which has a very low solubility ${ }^{20}$. Thus, it was necessary to heat this mixture in order to solubilize it, thus demanding a long time for completion of the reducing process (Table 3 ). In the case of ascorbic acid, $\mathrm{NH}_{4} \mathrm{OH}$ was used instead of $\mathrm{NaOH}$. Thus, a soluble complex is formed and there is more $\mathrm{Ag}^{+}$ available to be reduced ${ }^{20}$.

It should also be noted that the procedure of silver recovery using ascorbic acid does not require too much practice, specific knowledge or sophisticated equipments. Thus, its use seems to be viable, due to the high market value of the recovered silver. In addition, the reagents used are not expensive, since for every $150 \mathrm{~g}$ of 
treated silver residues, the cost is approximately around US\$ 12.00 . The amount of recovered silver is around $65 \mathrm{~g}$, and the cost to buy $1 \mathrm{~g}$ of $\mathrm{Ag}$ (99\% purity) is as high as US\$2.40. Thus, the recovery of silver using the proposed technique with reduction by ascorbic acid, in addition to reducing the environmental impact caused by the discharge of this metal into the ecosystem, can also provide additional resources to the laboratory that can be used in other investigations.

\section{CONCLUSIONS}

The developed methodology was shown to be viable, since it does not require sophisticated equipments or specialized personnel, and is a cost-effective alternative.

\section{ACKNOWLEDGEMENTS}

The authors thank FAPESP (\#2006/03164-0) for the concession of a scholarship to the first author and ODONTOPREV (Dental Services) for the financial support to this study.

\section{REFERENCES}

1- American Dental Association. Council on dental materials and devices. American Dental Association. Specification no. 1 for alloy for dental amalgam. In: Guide to dental materials. $2^{\text {nd }}$ ed. Chicago: ADA; 1964. p. 85.

2- Boyd AS, Seger D, Vannucci S, Langley M, Abraham JL, King LE Jr. Mercury exposure and cutaneous disease. J Am Acad Dermatol. 2000;43(1 Pt 1):81-90.

3- Ckelman MJE; Graedel TE. Silver emissions and their environmental impacts: a multilevel assessment. Environ Sci Technol. 2007;41(17):6283-9.
4- Drake PL, Hazelwood KJ. Exposure-related health effects of silver and silver compounds: a review. Ann Occup Hyg. 2005;49(7):575-85.

5- Edlich RF, Greene JA, Cochran AA, Kelley AR, Gubler KD, Olson $B M$, et al. Need for informed consent for dentists who use mercury amalgam restorative material as well as technical considerations in removal of dental amalgam restorations. J Environ Pathol Toxicol Oncol. 2007;26(4):305-22.

6- Gorsuch JW, Klaine SJ. Toxicity and fate of silver in the environment. Environ Toxicol Chem. 1998;17(4):537-8.

7- Harjula H. Hazardous waste: recognition of the problem and response. Ann N Y Acad Sci . 2006;1076:462-77.

8- Hiltz M. The environmental impact of dentistry. J Can Dent Assoc. 2007;73(1):59-62.

9- Hylander LD, Lindvall A, Uhrberg R, Gahnberg L, Lindh U. Mercury recovery in situ of four different dental amalgam separators. Sci Total Environ. 2006;366(1):320-36.

10- Iano FG, Sobrinho OS, Silva TL, Pereira MA, Figueiredo PJM, Alberguini PJMF, et al. Optimizing the procedure for mercury recovery from dental amalgam. Braz Oral Res. 2008;22(2):11924.

11- Lee CW, Fung KW. Recovery of silver and mercury from dental amalgam waste. Resource Recovery and Conservation. 1981;5:363-71.

12- Cenci MS, Pereira-Cenci T, Donassollo TA, Sommer L, Strapasson A, Demarco FF. Influence of thermal stress on marginal integrity of restorative materials. J Appl Oral Sci. 2008;16(2):10610.

13- Pécora JD, Silva RS, Souza RA, Guimarães LFL, Shuhama T. Recycling of dental amalgam residues for the recovery of mercury and silver. Rev Fola/Oral. 1998;4(14):234-7.

14- Pichay TJ. Dental amalgam: regulating its use and disposal. CDA Journal. 2004;32(7):580-2.

15- Purcell TW, Peters J]. Sources of silver in the environment. Environ Toxicol Chem. 1998;17(4):539-46.

16- Richards D. Amalgam, risk, benefits and the precautionary principle. Evid Based Dent. 2008;9(1):2.

17- Roig MG, Rivera ZS, Kennedy JF. L-ascorbic acid: an overview. Int J Food Sci Nutr. 1993;44:59-72.

18- Stone ME, Cohen ME, Berry DL, Ragain JC Jr. Design and evaluation of a filter-based chairside amalgam separation system. Sci Total Environ. 2008;396(1):28-33.

19- Triebold HO. Quantitative analysis. Read books: New York; 2007. p. 9-11.

20- Vogel AL. Vogel's qualitative inorganic analysis. $7^{\text {th }}$ ed. London: Longmans; 1996.

21- Webb NA, Shaw JR, Morgan J, Hogstrand C, Wood CM. Acute and chronic physiological effects of silver exposure in three marine teleosts. Aquatic Toxicol. 2001;54(3-4):161-78. 